\title{
A Forgotten Cause of Abdominal Pain
}

\author{
Maj RA Daoud \\ FRCS (Eng, Glas), RAMC \\ Specialist Registrar in General Surgery
}

\section{Dr H E Oakervee}

BSc, MRCP

Registrar in Medicine

Maj DM Bowley

FRCS, RAMC

Senior House Officer in General Surgery

MDHU Frimley Park Hospital, Portsmouth Road, Frimley, Surrey, GU16 5UJ

SUMMARY: A case of tuberculosis presenting as intestinal obstruction in a Gurkha soldier is reported and the difficulties of diagnosis discussed.

\section{Case Report}

A 28 year old Gurkha was admitted with 4 weeks history of intermittent colicky abdominal pain and diarrhoea. The latter settled prior to referral. At three days post admission, he continued to complain of abdominal pain with symptoms of small bowel obstruction.

$\mathrm{He}$ developed a swinging pyrexia of $40^{\circ} \mathrm{C}$ and a tachycardia of $100 / \mathrm{min}$. Blood pressure was mildly elevated at 158/95. Examination of his chest and heart was normal. His liver was palpable to $1 \mathrm{~cm}$ and there was generalised distension, tenderness and obstructive bowel sounds were heard on auscultation.

Haemoglobin 115g/l. White cell count $11.5 \times 10^{\wedge} 9 / 1$ with neutrophilia, monocytosis and lymphopenia. ESR $81 \mathrm{~mm} / \mathrm{h}$. C-reactive protein $254 \mathrm{mg} / \mathrm{l}$. Albumin $27 \mathrm{~g} / 1$. Amylase $56 \mathrm{u} / \mathrm{l}$.

Mantoux test was non reactive. Chest X-ray was initially normal but later showed small pleural effusions. Abdominal X-ray was compatible with small bowel obstruction. Computerised Tomography showed increasing pleural effusion, without focal chest or abdominal lesions. Early morning urine was negative for acid fast bacilli. Ziehl-Nielsen staining was performed on nasogastric and pleural aspirates and again these were negative.

Initially he was managed conservatively with nasogastric suction and intravenous fluids. He did not settle on this regime and laparotomy was performed. This revealed a large amount of peritoneal fluid, widespread minute peritoneal deposits and multiple adhesions involving the small bowel and causing mechanical obstruction. The adhesions were divided, appendicectomy and omental biopsy performed. The peritoneal fluid was sent for biochemical and bacteriological examinations.

The diagnosis of abdominal tuberculosis was made when the histology confirmed the characteristic granulomas of tuberculosis. Ziehl-Nielsen stain revealed few acid fast bacilli in the omental biopsy. Subsequently the mycobacterium was cultured from the peritoneal fluid. The patient was started on antituberculous treatment and made an uneventful recovery.

\section{Discussion}

Abdominal tuberculosis is not rare, nor is it confined to the poor, or patients with active pulmonary tuberculosis.? The condition should be considered in the differential diagnosis of abdominal pain (1).

The symptoms and signs are variable (2). In the presence of pulmonary tuberculosis the diagnosis of the condition would be readily thought of, however, this was not evident in our case. The association between pulmonary and abdominal tuberculosis varies widely and has been reported to range from $1 \%$ to $60 \%(3,4,5)$. As in this case others have found intestinal obstruction to be the presenting feature (6).

Laboratory investigations were reported to have little diagnostic value (2), as in the case with a negative Mantoux test. Mycobacterium tuberculosis is isolated more easily from biopsy samples than from ascitic fluid (3, 7). In this case the organism was not cultured from ascitic fluid for some eight weeks, a method clearly unsuitable for early diagnosis.

Direct visualisation and biopsy of the peritoneum provides a definitive tissue for diagnosis (8). Laparoscopic biopsy has been successfully reported by some centres $(3,8,9,10)$. However, in another series laparotomy was considered necessary to obtain diagnosis and relief obstruction in $81 \%$ of cases (11).

Abdominal tuberculosis therefore should be considered in cases of abdominal pain particularly among ethnic 
minorities in the United Kingdom and peritoneal biopsy appears to be the quickest and most definitive diagnostic test.

\section{Acknowledgments}

We would like to thank Col P Fabricius FRCP, late RAMC and Lt Col JG McAdam FRCS, RAMC for allowing us to report this case.

\section{References}

1. GitT S, Haddad F, Levenson S. Tuberculous peritonitis: an overlooked diagnosis. Hospitals Pract 1992; 27(1): 224-8.

2. SINGH V, JAIN AK, AGRAWAL AK, et al. Clinicopathological profile of abdominal tuberculosis. Br J Clin Pract 1995; 49(1): 22-4.

3. Nafeh MA, Medhat A, Abdul-Hameed AG, Ahmad YA, RASHWAN NM, STICKLAND GT. Tuberculous peritonitis in Egypt : The value of laparoscopy in diagnosis. Am J Trop Med Hyg 1992; 47(4): 470-7.

4. Chen YM, Lee PY, Perng RP. Abdominal tuberculosis in Taiwan: A report from Veterans' General Hospital, Taipei. Tubercle and Lung disease 1995; 76(1): 35-8.
5. LingenfFelser T, ZAK J, MARKS IN, SteYN E, HALKETR J, PRICE SK. Abdominal tuberculosis: still potentially lethal disease. Am J Gastroenterol 1993 0 . 88(5): $744-50$.

6. DAS P, SHUKLA HS. Clinical diagnosis of abdominap?. tuberculosis. Br J Surg 1976; 63:941-946.

7. MARShALL JB. Tuberculosis of the gastrointestinaf tract and peritoneum. Am J Gastroenterol 1993; 88 989-999.

8. Hossain J. Al-AsKa AK, AL-Mofleh I. Laparoscop in tuberculous peritonitis. $J R$ Soc Med 1992; 85(2) 89-91.

9. Wilairatana P, Wilairatana S. Lekhyananda Sひ Charoenlarp P. Does Laparoscopy have a limited. role in diagnosis of fibroadhesive tuberculous peritonitis? Southeast Asian J Trop Med Public Healt 1993; 24(4): 762-5.

10. MiMICA M. Usefulness and limitations of laparoscopy in the diagnosis of tuberculous peritonitis. Endoscop $\vec{\Delta}$. 1992; 24(6): 588-91.

11. GoKSOY E, DUREN M, UYGUN N. Gastrointestinat tuberculosis. 10 years experience in a surgica university clinic. Chirurg 1994; 65(6): 546-50. 